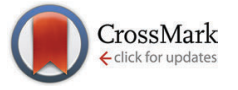

Cite this: Phys. Chem. Chem. Phys. 2015, 17, 29394

\author{
DOI: $10.1039 / c 5 c p 90186 c$
}

www.rsc.org/pccp

\section{Correction: Oxygen reduction and oxygen evolution in DMSO based electrolytes: the role of the electrocatalyst}

\author{
C. J. Bondue, ${ }^{a}$ P. Reinsberg, ${ }^{a}$ A. A. Abd-El-Latif ${ }^{a b}$ and H. Baltruschat*a
}

Correction for 'Oxygen reduction and oxygen evolution in DMSO based electrolytes: the role of the electrocatalyst' by C. J. Bondue et al., Phys. Chem. Chem. Phys., 2015, 17, 25593-25606.

The journal title in ref. 26 of the published article is incorrect. The correct reference is provided below:

\title{
References
}

1 M. Marinaro, P. Balasubramanian, E. Gucciardi, S. Theil, L. Jörissen and M. Wohlfahrt-Mehrens, ChemSusChem, 2015, DOI: $10.1002 /$ cssc.201500600.

The Royal Society of Chemistry apologises for these errors and any consequent inconvenience to authors and readers.

\footnotetext{
${ }^{a}$ Institut für Physikalische und Theoretische Chemie, Universität Bonn, Römerstraße 164, D-53117 Bonn, Germany. E-mail: baltruschat@uni-bonn.de

${ }^{b}$ National Research Centre, Physical Chemistry Department, El-Bohouth St. Dokki, 12311 Cairo, Egypt
} 